\title{
A Novel Technique for Administering Hamstring Donor- Site Analgesia during Anterior Cruciate Ligament Reconstruction
}

\author{
Douglas J Matthews, FRCS ${ }^{*}$ and Gil Railton, FRCS
}

Department of Trauma and Orthopaedic Surgery, Kingston Hospital, United Kingdom

\section{Introduction}

Postoperative pain following anterior cruciate ligament reconstruction can be mitigated by delivery of local anaesthetic along the hamstring harvest bed [1]. Initially described using an arthroscopic shaver sleeve to deliver the anaesthetic [2], subsequent techniques have described using suction catheter tubing [3]. However, the flexibility of suction tubing can cause problems advancing it along the harvest bed. We describe a novel technique for administering local anaesthetic to the hamstring donor-site.

\section{Technique}

A sterile packed anaesthetic bougie (Cook Medical LLC, Bloomington, USA) (Figure 1 ) is opened and kept sterile. The proximal end is cut toaccomodate a $20 \mathrm{ml}$ Luer slip-type syringe containing $0.25 \%$ Chirocaine (Figure 2, Figure 3 and Figure 4). The rigidity of the bougie aids passage along the tract of the hamstring donor-site and the local anaesthetic is injected as the bougie is withdrawn.

\section{Expected Outcome}

Patients have improved post-operative pain as expected from local anaesthetic delivery along the hamstring harvest site [1]. The rigidity of the anaesthetic bougie reduces difficulty passing it against the soft tissue envelope and minimises operative time to complete this important step. The malleability of the bougie enables it to be pre-bent to ease passage along the hamstring harvest site.

\section{Complications}

No complications have been experienced using this technique.

\section{Conflicts of Interest}

The authors declare no conflict of interests.

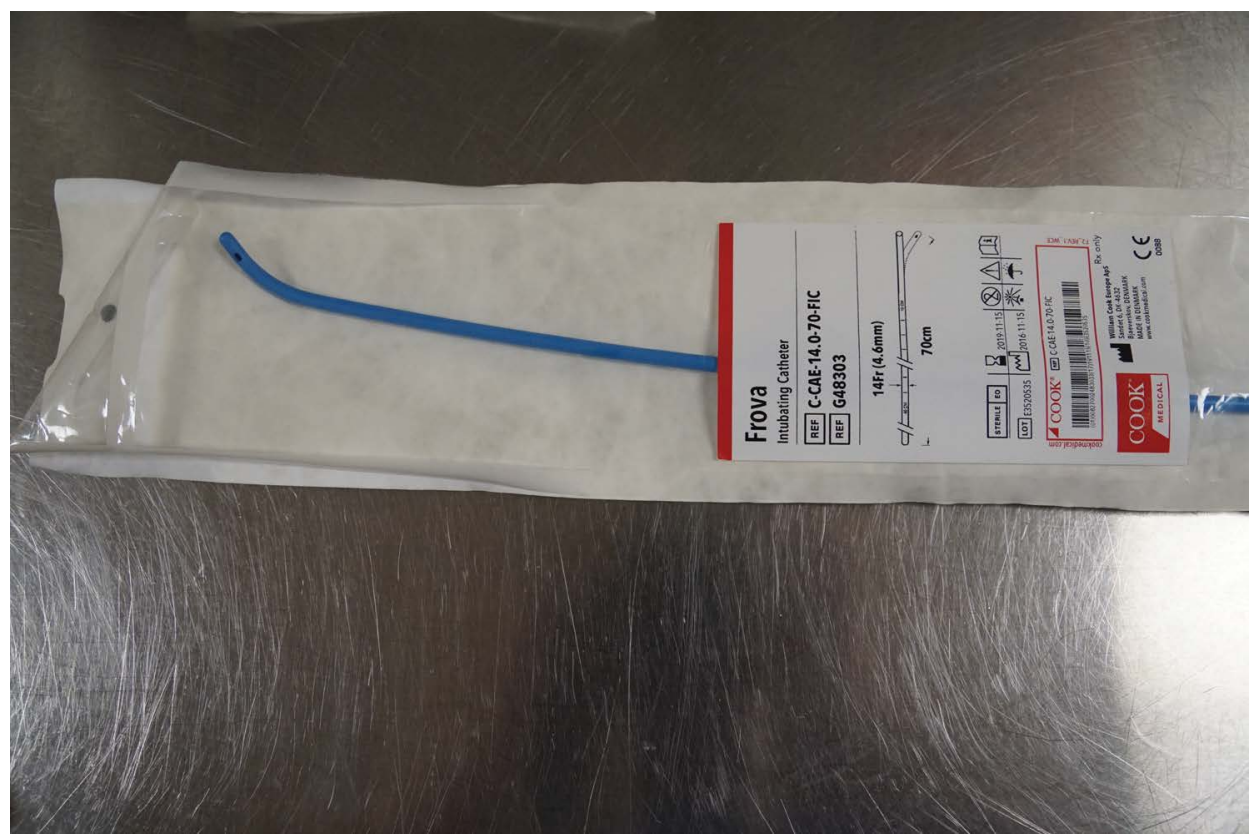

Figure 1: Sterile packed anaesthetic bougie. 


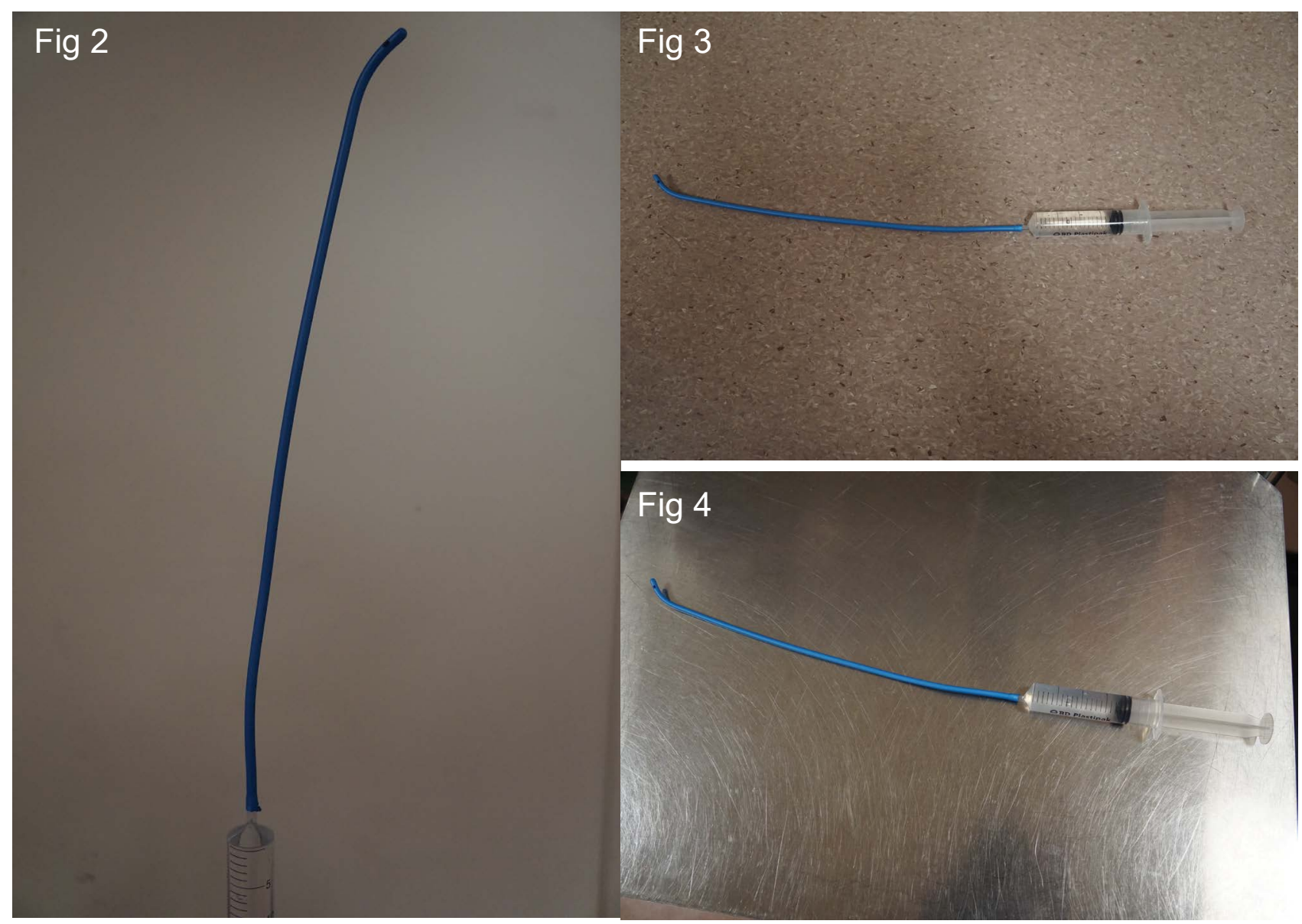

Figure 2, Figure 3 and Figure 4: Anaesthetic bougie cut proximally and attached to Luer slip-type syringe containing local anaesthetic.

\section{References}

1. Faun $\varnothing$ P, Lund B, Christiansen SE, et al. (2015) Analgesic effect of hamstring block after anterior cruciate ligament reconstruction compared with placebo: A prospective randomized trial. Arthroscopy 31: 63-68.

2. Bushnell BD, Sakryd G, Noonan TJ (2010) Hamstring donor-site block: Evaluation of pain control after anterior cruciate ligament reconstruction. Arthroscopy 26: 894-900.

3. Logan JS, Elliot RR, Wilson AJ (2011) A new technique for hamstring donor site blockade in anterior cruciate ligament reconstruction. Annals of the Royal College of Surgeons 93: 326.
*Corresponding author: Douglas J Matthews, Department of Trauma and Orthopaedic Surgery, Kingston Hospital Galsworthy Road, Kingston Upon Thames KT2 7QB, UK

Accepted: February 01, 2021

Published online: February 03, 2021

Citation: Matthews DJ, Railton G (2021) A Novel Technique for Administering Hamstring Donor-Site Analgesia during Anterior Cruciate Ligament Reconstruction. J Orthop Surg Tech 4(1):237238

DOI: $10.36959 / 453 / 553$

Copyright: (C) 2021 Matthews DJ, et al. This is an open-access article distributed under the terms of the Creative Commons Attribution License, which permits unrestricted use, distribution, and reproduction in any medium, provided the original author and source are credited. 